\title{
Effectiveness of Financial Literacy Interventions Provided to Homeless; Will It Increase Self-sufficiency?
}

\author{
Natasha Price, Shanika Lavi Wilson* and Christopher Solomon \\ North Carolina Central University, North Carolina, USA
}

*Corresponding author: Shanika Lavi Wilson, North Carolina Central University, North Carolina, USA, Tel: (919) 4237952; E-mail: swils108@NCCU.EDU

Received Date: June 19, 2019; Accepted Date: June 30, 2019; Published Date: July 07, 2019

\section{Introduction}

Financial literacy can empower clients who experience homelessness. Individuals who learn financial literacy are informed about their current financial crisis, current budget, past financial issues, and will provide budget tips, coping skills, and informative information becoming self-sufficient by becoming aware of financial status and financial needs. Homelessness is a social problem that affects every race, culture, economic level, and it affects the macro level, micro level, and mezzo level. Although research shows, rates are higher for non-Hispanic blacks or Hispanics than non-Hispanic whites; everyone is affected [1].

Individuals in homeless shelters or facilities that do not receive effective interventions or resources to increase empowerment that increases self-sufficiency may return or remain in that location. Studies show that financial literacy may decrease poverty as a person becomes more aware of their money management skills, and their financial issues [2]. Individuals may be homeless due to loss of income, housing, and domestic violence. That means these individuals are less likely to become empowered, reach self-sufficiency and more likely to return to the shelter environment without the proper interventions and support systems including therapy. Clients who have failed to manage finances can lead to bankruptcies and home foreclosures causing clients to become homeless [3]. Hawkins \& Kim [2] study proposed that many financial literacy programs do not address underlying cultural attitudes, family history, or things that influence client financial status. Financial literacy is the ability to make an educated decision about using money in the present and the future [4]. By providing resources and intervention to promote financial literacy will increase self-sufficiency, provided resources to community and address poverty. Hetling [4] found financial literacy empowers clients to become self-sufficient. The homeless population could benefit from financial literacy as it will increase their knowledge of their current financial crisis and future financial standing. Financial literacy will provide the coping skill to help with spend urges. Bowen et al., found that in obtaining financial literacy a client will not only be able to beat the odds but more importantly change the odds. According to Hetling \& Posmust [4], financial literacy will not only empower but will provide clients with informative

Citation: Natasha Price, Effectiveness of Financial Literacy Interventions Provided to Homeless; Will It Increase Selfsufficiency?. J Clin Cases Rep 2(S1): 6-10. DOI: https://doi.org/10.46619/joccr.2019.2.S1-1003 
http://www.tridhascholars.org | December-2019

information on things such as budgeting, spending habits and knowing how to save. The literature focuses on barriers that the homeless face such as; the ability to access financial literacy, adequate housing, and empowerment, however, less research focuses on the small percentage of homeless that receives adequate interventions and do not return to the shelter environment. Therefore, this project will focus on understanding the effectiveness of self-sufficiency by obtaining financial literacy.

\section{Scope of the Problem}

Homelessness is a major social problem that has an impact, everyone, whether directly or indirectly through family member or friend. Homelessness has a significant effect on everyone regardless of race or status. The literature states that $3 \%$ of Americans will experience homelessness blacks having the highest rate to experience homelessness [1,5]. In the state of North Carolina, there are 8962 people homeless on any given night. In 2016, there were over 560,000 people in the United States and 35000 in Canada [6]. Homelessness is a social problem the world should address more vigorously. There needs to be more research on the interventions needed to prevent homelessness and decrease homelessness. This community project will discuss the effects of financial literacy workshops on individuals who are currently experiencing homelessness will help the researcher find a viable solution to the social problem of homelessness. The research will assess the barriers of the homeless and what the client needs to become self-sufficient.

\section{Justification and Purpose of the Proposed Study}

Researching financial literacy can decrease homelessness and increase self-sufficiency in shelter settings will affect the world on many levels. Homelessness is not only a community problem, but as mentioned above it affects cities and towns, states, and districts. In fact, according to the End Homeless website in 2017 the United States estimated to have had 553,742 homeless individuals. The study will address interventions that will empower clients, and participants will receive resources to become financially literate to obtain adequate housing (National Alliance to End Homelessness (2016). The purpose of this community project is to provide financial literacy to clients who are experiencing homelessness. The study will utilize center for Financial Social Work Financial Literacy Activity that is valid and reliable and will also assist clients in becoming self-sufficient.

\section{Chapter Two: Literature Review}

Homelessness is a social problem that impacts the world. According to the National Alliance to End Homelessness (2016), over 450,000 people affected by homelessness directly. Homelessness occurs because of housing inadequacy, substance abuse, changes in income, unemployed and domestic violence. Homelessness can happen to anyone whether single, married, working, even those receiving benefits from the military [7,8]. The literature review is divided into three sections; Financial Literacy, Self-Sufficiency and Shelter re-entry.

\section{Financial Literacy}

Postmus et al. [3] defined financial literacy as the knowledge gained from financial education. Financial literacy according to Hetling and Postmus [4] is the ability to make educated decisions about using money in the present and the future. Both studies reported that financial literacy is critical today as tomorrow leaders do not know how to save or budget. Financial education includes learning to budget, balance checkbooks, invest and learn to make financial choices [3]. There is limited research on financial literacy in America and how it helps the homeless become self-sufficient. Postmus et al. [3] found 
http://www.tridhascholars.org | December-2019

financial literacy needs improvement and that financial illiteracy has occurred because of the lack of budgeting. The researchers used a financial literacy scale that measured knowledge of financial topics. In their research, they found that positive and significant relationships between financial literacy economic and empowerment to become self-sufficient. Their study also showed that women are more risk of experiencing a situation that leave them in worse financial shape than men [3].

Having financial literacy is beginning to become a critical issue in the world. The set-up of fiscal irresponsibility is a financial disaster waiting. In 2003, there was six states bill that passed that mandated financial education in schools and in 2003 the Title V of the Fair and Accurate Credit Transactions act was recognized to happen. According to Bowen \& Jones, the critical need for financial literacy to resolve the debt may have caused decision makers and state policymakers to look more closely at the benefits of financial literacy. These policymakers state that financial education will change the nations' financial literacy. The Financial Literacy and Education Improvement Act (2003) has made personal finance education priority by coordinating federal efforts and providing strategies to address financial literacy efficiently.

\section{Inadequate Housing}

A basic need for every individual in the world is to have adequate housing for one to live safely in a safe community. Quilgars and Pleace [9] found that housing is one of the leading causes of homelessness. The lack of adequate housing has increased over the last ten years because individuals are poor, are currently in a poor living condition and are paying more than $50 \%$ of their income for rent [10]. In 2013, the Housing and Urban Development reported in the Annual Homelessness Assessment report that there were an estimated 610,042 without any housing [11].

Many transitional services partner up with housing agencies such as HUD, Income-based homes and affordable housing agencies. These programs exist to help those that are experiencing homelessness and those who do not have adequate housing. The programs assist clients with their rent and may provide utility checks to assist with heating and cooling. Lewinson, et al. [12], found women live in budget hotels to avoid being out on the streets which may cause a financial crisis. It is evident that obtaining proper housing is critical when discussing homeless individual those who live on the streets and those who are in transition.

\section{Recurrent Homelessness}

Recurrent homelessness is as an overnight stay in the shelter within one year of obtaining housing and being discharged from the shelter [5,13]. Duchesne \& Rothwell [13] found that about 40\% of homeless person returns to the shelter within a year because clients leave the shelter to soon, clients did not receive adequate resources or interventions to reach selfsufficiency before discharge. In 2013, Gorroochurn, Hsu, and Caton's study found that substance abuse was a significant factor in recurrent homelessness [5]. Many clients are discharged because of their constant drug usage in out of the shelter [5]. Studies show that the length of time spent homeless and the total occurrences of homelessness experienced will impact the course of one's life after transitioning back into stable living [11]. Many of the individuals may not return to the shelter but to live with friends and family or hotel. Budget hotels are a refuge for homelessness who have a constant cycle of living in shelters, with family and friends, in their car or just on the streets [13].

\section{Theoretical Framework}


http://www.tridhascholars.org | December-2019

The theory that utilized in the study will be is the Empowerment Theory. According to Coady and Lehmann, the empowerment theory was birth from the work of Barbara Solomon and later the works of Judith Lee and Lorraine Gutierrez, Ruth Parsons, and Enid Cox. The empowerment of people is a very crucial factor in keeping the world spinning. Christen [14], described empowerment to be a collaboration to work with individuals, organizations, and communities to achieve a higher social justice and community wellness. Empowerment occurs in every career; however, it is the heart of the social work field. In National Association of Social Workers (NASW) Code of Ethics (2017), it states "the primary mission of the social work profession is to enhance human well-being and help meet the basic human needs of all people, with particular attention to the needs and empowerment of people who are vulnerable, oppressed, and living in poverty. The researcher applied the empowerment theory at the individual level, community level, and organization level and its focus on intrapersonal work [14]. The Empowerment Theory has been used to promote self-efficacy. As applied to the study, this theory provides a lens for understanding the effectiveness of interventions that empower every area of the participant's life. "Utilizing a theory that empowers the client to become self-sufficient is the focus of this study along with other interventions". Coady \& Lehmann 2016, in their study, stated that the Empowerment interventions might help individuals to develop self-sufficiency psychologically or coping skills to adjust but it's not sufficient to overcome powerlessness. This theory connects to my research as by promoting financial freedom we are empowering clients to become self-sufficient. Interventions are to empower clients. Financial literacy will empower clients to critically think about their finances and come up with a plan.

\section{Implications for Social Work Practice}

It is imperative that social workers teach their clients about financial literacy. By teaching financial education clients will learn their negative spending habits, learn budgeting tips and become self-sufficient. The research such that financial literacy will help the economy. Social workers should be educated on financial literacy as it will help the field of social work and further research of financial literacy will help the world. Social workers should complete more research about financial education and the effectiveness. There is a limited amount of research on what the best way to deliver and if a course of a few hours length or should we incorporate over a life span. Financial education will effective homeless rates as clients apply the knowledge gained about financial literacy, they learn how to budget and pay their bills, learn how to avoid making rash purchases. Financial literacy will allow the homeless population to learn to manage their income and become financially educated on their debt to debt ratio. Steen and Mackenzie [15], found that by providing financial literacy can impact financial stress and help those risk of homelessness. They suggested that homelessness may result from loss personal financial, and social resources. In fact, the loss of employment, previous financial experiences, and overall lack of financial literacy. As social worker working with this population homeless population would benefit from a life-span of financial literacy. Social worker should provide clients with resources to obtain financial education and clients should continue to use resources once stable.

\section{References}

1. Fusaro VA, Levy HG, Shaefer HL (2018) Racial and ethnic disparities in the lifetime prevalence of homelessness in the United States. Demography 55: 2119-2128.

2. Hawkins RL, Kim EJ (2012) The socio-economic empowerment assessment; addressing poverty and economic distress in clients. Clinical Social Work Journal 40(2): 194-202. 
http://www.tridhascholars.org | December-2019

3. Postmus JL, Plummer S, Mcmahon S et al. (2012) Financial literacy: building economic empowerment with survivors of violence. Journal of Family and Economic Issues 34(3): 275-284.

4. Hetling A, Postmus J (2014) Financial literacy and economic empowerment of survivors of Intimate partner violence: Examining the differences between public assistance recipients and nonrecipients. Journal of Poverty 18: 130-149.

5. McQuiston HL, Gorroochurn P, Hsu E, et al. (2013) Risk factors associated with recurrent homelessness after a first homeless episode. Community Mental Health Journal 50(5): 505-513.

6. Pankratz C, Nelson F, Morrison M (2017) A quasi-experimental evaluation of rent assistance for individuals experiencing chronic homelessness. Journal Community Psychology 45(8): 1065-1079.

7. Fargo JD, Munley EA, Byrne TH, et al. (2013) Community-Level characteristics associated with variation in rates of homelessness among families and single adults. American Journal of Public Health 103(2): 340-347.

8. Cusack M, Montgomery AE (2017) The role of eviction in veterans' homelessness recidivism. Journal of Social Distress and the Homeless 26(1).

9. Quilgars D, Pleace N (2016) Housing first and social integration: a realistic aim? Social Inclusion 4(4): 5-15.

10. Cunningham M, Pergamit M (2015) Housing matters for Families: promising practices from Child welfare agencies. Child Welfare 94(1): 123-140.

11. Castellow J, Kloos B, Townley G (2015) Previous homelessness as risk factor for recovery from serious mental illnesses. Community Mental Health Journal 51(6): 674-684.

12. Lewinson T, Thomas ML, White S (2014) Traumatic transitions: homeless women's narratives of abuse, loss, and fear. Journal of Women and Social Work, 29(2): 192-205.

13. Duchesne AT, Rothwell DW (2016) What leads to homeless shelter re-entry? An exploration of the psychosocial, health, contextual and demographic factors. Canadian Journal of Public Health 107: e94-e99.

14. Christens BD (2012) Toward relational empowerment. American Journal Community Psychology 50(1-2): 114-128.

15. Steen A, MacKenzie D (2013) Financial stress, financial literacy, counselling and the risk of homelessness. Australasian Accounting, Business and Finance Journal 7(3): 31-48. 